\title{
Os alunos das redes pública e particular do Ceará em tempos de pandemia na visão dos professores de línguas estrangeiras
}

\author{
Public and private students in Ceará in times of pandemics in the view of foreign language teachers
}

\section{Andreia Turolo da Silva}

Universidade Federal do Ceará - UFC - Ceará- Brasil

\section{Albert Cristian Dutra da Mota}

Universidade Federal do Ceará - UFC - Ceará- Brasil

\section{Náyla Naira Brito Nobre}

Universidade Federal do Ceará - UFC - Ceará- Brasil

\section{Yana Valéria Bezerra de Freitas Ferreira}

Universidade Federal do Ceará - UFC - Ceará- Brasil

\begin{abstract}
Resumo: Este é um estudo de caráter diagnóstico e de natureza qualitativa que teve como objetivo verificar a adesão dos alunos das redes pública e particular às atividades das disciplinas de língua estrangeira propostas no modo remoto como forma de ensino emergencial durante os meses iniciais da pandemia no estado do Ceará e as razões que pudessem justificar a adesão satisfatória, baixa ou ausência dos estudantes do ponto de vista dos professores. Para isso, foi aplicado um questionário no formato digital, que foi respondido por duzentos professores de língua inglesa e espanhola oriundos de vários municípios do estado, além da capital, Fortaleza. O questionário foi respondido de forma anônima e voluntária a partir de grupos on-line de professores de idiomas do estado e as respostas apontaram para uma adesão satisfatória dos estudantes da rede privada, justificada pelas condições estruturais e familiares favoráveis, além do hábito dos estudantes de lidar com tecnologias digitais anterior à pandemia. Na rede pública, os professores avaliaram a adesão dos estudantes como média-baixa e a justificaram pela carência de condições estruturais e familiares dos estudantes, além da dificuldade de lidar com tecnologias, principalmente pela falta de hábito e baixa autonomia. Entre outros fatores que os professores apontaram como desejáveis para o bom ensino no modo remoto emergencial, o apoio da família foi destacado como meio de compensar a falta de autonomia dos estudantes.
\end{abstract}

Palavras-chave: Educação a Distância; Tecnologias no Ensino de Línguas; Língua Estrangeira; Ensino Básico; Pandemia do Coronavírus.

\begin{abstract}
This is a diagnostic qualitative study that aimed at verifying the students' adherence, both from public and private schools, to the activities of the foreign language disciplines proposed in the remote way as a form of education emergency plan during the initial months of the coronavirus pandemics in the state of Ceará, and the reasons that could justify their satisfactory participation, low participation or absence of participation from the point of view of their language teachers. For this, a questionnaire was applied in the digital format, which was answered by two hundred English and Spanish teachers from several municipalities in the state of Ceará, besides its capital Fortaleza. The questionnaire was answered anonymously and voluntarily in online groups of language teachers of Ceará and the answers pointed to a satisfactory adherence of private school students, justified by favorable structural and family conditions, in addition to the students' habit of dealing with digital technologies prior to the pandemics. In public schools, teachers evaluated the students' adherence as medium-low, and justified it by the lack of structural and family conditions of the students, in addition to the difficulty of dealing with technologies, mainly due to the lack of habit and low autonomy. Among other factors that teachers pointed out as desirable for good teaching and learning in the remote emergency plan, family support was highlighted as a way to compensate for the lack of students' autonomy.
\end{abstract}


Keywords: Distance Education; Technologies in Language Teaching; Foreign Languages; Basic Education; Coronavirus Pandemics.

\section{Introdução}

Ao passo que o novo coronavírus (Sars-CoV-2) expandiu-se por vários países, as populações necessitaram reconfigurar os seus modi operandi. A rotina de ir ao trabalho, às instituições de ensino e aos locais públicos foi substituída pela permanência em casa, obedecendo a decretos mais ou menos rígidos que estabeleceram o isolamento social como principal meio de enfrentamento da pandemia do novo coronavírus. Muito embora todos nós, seres humanos, estejamos biologicamente sujeitos às consequências provocadas pelo vírus, outros fatores também perpassam o cenário pandêmico e devem ser considerados.

Um grande fator de relevância é o socioeconômico, o qual evidencia grupos que são atingidos em menor ou maior escala. Há de convirmos que alguém que possui condições minimamente ideais de moradia, saúde, educação e segurança terá maior probabilidade de atravessar o atual cenário pandêmico com menor prejuízo em comparação àquele que não dispõe desses acessos. A pandemia, portanto, passa a acentuar os processos de desumanização daqueles que por tempos são tidos como invisíveis à sociedade, como afirma Santos (2020), e cada vez mais zonas de invisibilidade se disseminarão em diversas regiões do mundo, possivelmente até mesmo a um alcance próximo de onde vivemos. Na cidade de Fortaleza, por exemplo, de acordo com o boletim epidemiológico emitido pela secretaria de saúde municipal do dia 03 de julho de 2020, enquanto o número de pessoas infectadas ainda liderava em regiões de maior IDH, o índice de letalidade era maior em regiões de menor IDH.

Assim como as mais variadas esferas da sociedade, como a saúde, a segurança e a indústria, a educação também tem sofrido impactos diretos $\mathrm{e}$ imediatos com a pandemia. Esses impactos abarcam a vida dos discentes, dos docentes e da gestão escolar, assim como a forma de interação entre esses grupos. Dada a impossibilidade de encontros in loco, as instituições de ensino públicas e privadas vêm adaptando e readaptando o fazer pedagógico por meio de ferramentas eletrônicas que necessitam de acesso à internet conforme desafios e demandas emergem; é exatamente a partir daí que as zonas de invisibilidade desses grupos são realçadas, principalmente no meio público.

Em uma reportagem publicada em um jornal local, a jornalista Domitila Andrade lista uma série de aspectos do cenário do ensino remoto na rede pública de ensino do estado durante a pandemia da Covid-19, resultado de um estudo realizado pela Undime-CE que mapeia que até $40 \%$ dos estudantes da rede municipal de ensino não têm nenhum tipo de acesso à internet em suas residências, e que um em cada quatro alunos que tem acesso à internet o faz somente pelo telefone celular com pacote de dados móveis, o que tem levado professores a optarem pela interação possível com esses estudantes apenas por meio do aplicativo WhatsApp.

A reportagem aponta, ainda, que não somente a falta de acesso à internet dificulta as atividades escolares no modo remoto, mas também a organização da estrutura familiar, muitas vezes já marcada pela vulnerabilidade, em que famílias numerosas coabitam em residências de um ou dois cômodos e que, portanto, não permitem aos estudantes um espaço adequado para realizar as atividades escolares: em escala nacional, $57 \%$ dos estudantes são moradores em favelas ou comunidades e $24 \%$ dos estudantes não estão tendo acesso a nenhum tipo de conteúdo ou interação com a escola e professores durante a pandemia. As razões identificadas no estudo são falta de acesso à internet (23\%), dificuldade de acompanhar o conteúdo recebido $(20 \%)$, falta de equipamentos tecnológicos $(15 \%)$ e falta de interesse em realizar as atividades no modo remoto (15\%).

Ainda de acordo com a reportagem, no interior do estado do Ceará, alguns municípios têm buscado soluções junto às suas secretarias de educação por meio da produção e distribuição de material impresso aos estudantes e apostado na interação professor- 
estudante por meio do aplicativo de WhatsApp para atingir, pelo menos, $75 \%$ dos estudantes. Na capital do estado, Fortaleza, a secretaria da educação também tem buscado formas alternativas de alcançar o maior número possível de estudantes por meio da distribuição de materiais impressos e interação professor-estudante-família por meio do aplicativo Whatsapp e estima que apenas $3 \%$ dos estudantes não estão conseguindo acesso de forma alguma. Outras soluções encontradas têm sido os meios analógicos de rádio e televisão locais. Andrade (2020), no entanto, pondera que ainda há a necessidade de uma pesquisa mais robusta sobre as zonas de invisibilidade para que os estudantes ausentes no modo remoto sejam identificados e que se busquem outras alternativas para inseri-los, o que ainda, segundo a autora, não foi feito.

Em outra reportagem publicada pelo mesmo jornal, Italo Cosme (2020) relata que professores acompanharam agentes municipais na entrega de cestas básicas às populações mais carentes de Fortaleza para poderem atualizar os contatos com os estudantes de suas escolas. $\mathrm{Na}$ reportagem, os professores entrevistados mencionaram que encontraram estudantes que não dispunham de nenhum meio tecnológico para contato e deixaram números de telefones de vizinhos.

Os professores relatavam que outro desafio era o baixo letramento dos pais das crianças que não conseguiam entender as mensagens escritas para ajudarem a mediar a aprendizagem, o que consideram necessário para o andamento do ensino remoto com crianças pequenas, principalmente as que estão em fase de alfabetização. As alternativas para alcançarem os pais das crianças têm sido mensagens de áudio e vídeo com instruções e comandos. Ainda assim, uma das professoras afirma que, de sua turma de vinte e dois alunos, apenas três estavam participando das atividades no momento em que a reportagem foi realizada (13 de julho de 2020). Reportagens como essas canalizam a atenção para as camadas invisibilizadas da nossa sociedade no amplo debate sobre as formas de continuar a educação durante a pandemia no modo remoto emergencial. Porém, muito ainda há para ser feito.

Observando e dialogando informalmente com professores do universo do ensino de línguas estrangeiras - nossa área de interesse - temos verificado várias limitações e desafios dos professores para ensinar suas disciplinas no contexto pandêmico. Apesar de encontrarmos tecnologias presentes no ensino de idiomas em vários contextos de ensino de modo significativo, demarcando, inclusive, uma área específica de prática e pesquisa denominada CALL, do inglês, Computer-Assisted Language Learning, verificamos muitos professores com dificuldades de lidarem com tecnologias digitais. Observamos o que Prensky (2010) denomina "digital divide": para aqueles que Prensky denomina "nativos digitais", as dificuldades possivelmente emergem majoritariamente no nível de adaptação pedagógico-metodológica de suas práticas. Por outro lado, os "imigrantes digitais" necessitam se habituar com maiores demandas no que diz respeito ao manejo dos ambientes virtuais para que consigam interagir com estudantes e gestores.

Nesse contexto complexo da pandemia do novo coronavírus, propomos investigar de que modo, do ponto de vista dos professores das redes pública e particular, os estudantes têm aderido ao plano emergencial de ensino de línguas estrangeiras no modo remoto, principalmente mediado por tecnologias digitais, e as razões para a sua adesão. Esperamos que os resultados desta pesquisa diagnóstica possam elucidar reflexões sobre os desafios de continuar a educação em nível básico durante e após a pandemia. Discutimos, a seguir, questões sobre o ensino de línguas mediado por tecnologias digitais. Logo após, descrevemos a metodologia deste estudo, os resultados da pesquisa realizada e finalizamos com reflexões e encaminhamentos.

\section{ENSINO DE LÍNGUAS MEDIADO POR TECNOLOGIAS, EDUCAÇÃO A DISTÂNCIA E ENSINO REMOTO}

Muito tem sido discutido sobre a inserção de tecnologias digitais na educação nas últimas décadas. 
Para a sociedade como um todo, as Tecnologias Digitais da Informação e Comunicação (doravante TDICs) não são apenas ferramentas utilizadas para trazer comodidade, elas modificaram o cotidiano dos cidadãos e da sociedade em rede. Conectada, esta nova sociedade apresenta novos comportamentos, novos movimentos sociais e novas manifestações de cultura, reconhecida como cibercultura. Isso porque, com a popularização das TDICs, novas práticas sociais se desenvolvem dia a dia, possibilitando que indivíduos interajam com outros usuários da rede lendo notícias, opinando, reivindicando, produzindo conhecimento, divulgando informações e se mobilizando.

Nas pesquisas sobre ensino-aprendizagem de línguas mediado pelo computador (CALL, mencionado na introdução deste estudo) destacamos Warschauer (1997, 1998), Levy (2000), White (2003) e Lamy e Hampel (2007), que realizaram extensivos estudos sobre a comunicação mediada pelo computador (doravante $\mathrm{CMC}$ ) e a aprendizagem de línguas, salientando vantagens e limitações nesse tipo de ensino. Entre as vantagens, destacam-se a participação igualitária e democrática, livre escolha e iniciativa, autonomia, pressão psicológica e ansiedade minimizadas por um ambiente caracterizado por tempos e espaços mais relaxados e flexíveis em comparação com a sala de aula tradicional.

Alguns resultados das pesquisas em CALL mostram a aprendizagem pela ação colaborativa, a maneira como a CMC promove oportunidades aumentadas para que os alunos negociem as formas e os significados da língua-alvo, a maneira como a CMC possibilita a negociação e a resolução de conflitos por meio de ações colaborativas, assim como as próprias tarefas de aprendizagem. Muitas dessas pesquisas têm base na teoria sociocultural de aprendizagem oriunda das interpretações sobre a obra de Vygotsky ([1934] 2000) aplicadas ao ensinoaprendizagem de línguas adicionais (LANTOLF, 2000).

Outra vantagem apontada em resultados das pesquisas em CALL é a oportunidade de interação com usuários da língua, seja como língua materna ou falantes de diferentes línguas comunicando-se por meio da língua-alvo de aprendizagem quando há acesso à internet. Nesse contexto de comunicação multicultural, aponta-se a importância do reconhecimento e da valorização das identidades dos aprendizes como fundamentais na aprendizagem da língua-alvo, principalmente em países que vivem questões relacionadas ao multilinguismo devido aos movimentos migratórios da atualidade (BELZ, 2001; WHITE, 2003).

Entre as restrições, as pesquisas apontam o sentimento de distância dos alunos, sobretudo em interações no modo remoto; o modo de comunicação visual reduzido, quando a $\mathrm{CMC}$ é predominantemente escrita; dificuldades com as tecnologias e os letramentos necessários que acarretam novas demandas que muitas vezes se impõem sobre uma cultura de aprender ainda tradicional, resultando em conflitos e desigualdades que precisam ser compreendidos (LAMY \& HAMPEL, 2007). Nesse sentido, as restrições da CMC impactam diretamente na construção da presença dos participantes nos ambientes on-line e na construção de um sentimento de pertencimento a um grupo de aprendizagem (LAVE \& WENGER, 1991.

Esses pontos cruciais da discussão sobre CALL, que também incluem o tratamento dado aos conteúdos e às formas de expressão mediadas por materiais didáticos em meios tecnológicos e que, portanto, demandam formas de avaliação diferenciadas, devem ser compreendidos de modo integrado, principalmente quando associados à Educação a Distância (doravante EaD), a qual, por sua vez, tem suas características próprias que precisam ser levadas em consideração.

Um dos aspectos mais ressaltados nos primeiros estudos sobre $\mathrm{EaD}$ é a distância entre professor e aluno, ao mesmo tempo em que se atribui um papel significativo às tecnologias, que podem ser impressas, analógicas, digitais, ou uma combinação delas, para que se criem meios de interação entre professores e estudantes que rompam a separação física. Em outra concepção de EaD, vemos uma ênfase no processo bidirecional, que implica uma 
retroalimentação da comunicação entre professores e estudantes, um processo dialógico de construção do conhecimento, em vez da noção de ensinoaprendizagem como transmissão da informação. $O$ papel de um aprendiz ativo é também enfatizado:

A educação a distância é um sistema tecnológico de comunicação de massa e bidirecional, que substitui a interação pessoal, em aula, de professor e aluno, como meio preferencial de ensino, pela ação sistemática e conjunta de diversos recursos didáticos e o apoio de uma organização tutorial, que propiciam a aprendizagem autônoma dos estudantes (GARCIA ARETIO, 1987, p. 79).

Além das noções como distância espacial entre professor e estudante e o papel do aprendiz ativo e autônomo, o uso das TDICs é também uma das características principais da EaD na atualidade. De acordo com Belloni (2002), devemos estar atentos ao papel das tecnologias na educação no sentido de como elas podem colaborar para o planejamento de ensino e para a produção de materiais, entendendo que as tecnologias precisam sempre ser adequadas às práticas de ensino-aprendizagem para que promovam inclusão, reflexão e diálogo.

Belloni (2002) considera que o eixo central da EaD é a "integração" das tecnologias, dos participantes e dos processos educacionais. A autora é cuidadosa sobre as definições de EaD que se apoiam na comparação com a educação presencial, assim como as definições que se apoiam apenas no uso das tecnologias. Para ela, as tecnologias são conjuntos de dispositivos técnicos que têm uma linguagem própria (informática) que inevitavelmente transformam as relações de quem as usam e, portanto, as suas práticas sociais e discursivas. Belloni (2002) preocupase com essas transformações sociais e salienta que esses são os aspectos mais significativos com os quais os educadores devem se preocupar, tanto na EaD quanto na educação presencial mediada por tecnologias.

Há também a necessidade de considerar o desenvolvimento das metodologias de ensino como essenciais para o sucesso de qualquer experiência com a EaD, conforme salienta Mota (2009). Este autor propõe que EaD é apropriada para jovens e adultos, e que se deve levar em consideração pelo menos quatro aspectos: (i) o autoconceito, ou a autopercepção; (ii) a experiência como preparação para o aprendizado; (iii) a orientação dos processos em direção ao aprendizado por meio de problematizações da vida cotidiana; e (iv) a motivação para aprender que os aprendizes adultos trazem. Segundo Mota (2009, p. 297-298), esses quatro pilares são necessários para que se promova a autonomia desejada do aluno, métodos eficazes, conteúdos relevantes e foco no processo.

Discutir a Educação a Distância (EaD) demanda, portanto, um olhar cuidadoso sobre as interações dos participantes com o processo ensinoaprendizagem e com fatores contextuais que interferem na construção dos espaços de aprendizagem. Esses fatores podem ser entendidos como o próprio aprendiz, o professor/formador, o tutor, os materiais didáticos, as tecnologias, bem como os processos de mediação pedagógica e de gestão, de maneira mais ampla (MOREIRA, 2009).

Tendo em vista as pesquisas trazidas, vemos que, mesmo antes do período de suspensão das aulas presenciais devido à pandemia do novo coronavírus, o papel das TDICs já vinha sendo bastante discutido na educação, na $\mathrm{EaD}$ e no ensino de línguas. Especificamente sobre o ensino de línguas, outra discussão relevante acerca da integração de TDICs é a valorização dos aspectos visuais presentes em textos (NASCIMENTO et al, 2011). Argumenta-se que, na composição dos textos, o modo escrito não pode ser considerado sozinho, pois encontra-se integrado às imagens e aos gráficos que compõem textos multimodais repletos de significados. Para além disso, Nascimento et al (2011) defendem que não existem textos monomodais, porque mesmo quando há predominância verbal, outros recursos semióticos são utilizados (tipografia e formatação, por exemplo).

Ao observarmos os gêneros textuais praticados no ambiente virtual, por meio dos conteúdos audiovisuais em sites, blogs, anúncios pop up, memes, para citarmos alguns exemplos, percebemos que não 
podemos continuar lidando com o ensino de línguas somente como sistema verbal. Walker e White (2013, p. 130) apontam que vivemos em uma cultura visual em expansão. Assim, para que os estudantes possam entender e produzir textos multimodais, é necessário discutir o papel do professor nesse processo, os seus letramentos e os letramentos dos aprendizes de modo que deixem de ser consumidores para se tornarem produtores críticos de textos (NASCIMENTO et al, 2011, p. 531), capazes de reconhecer e interagir com "diferentes modos de significação e uma multiplicidade de aspectos que compõem um universo sociocultural" (KNOLL, 2015, p. 58).

Como estamos passando por um momento em que muitas instituições educacionais estão realizando suas atividades remotamente, é importante pensar questões relacionadas aos modos de receber e produzir textos digitais, que acarretam, portanto, na noção de letramentos digitais. Destacamos que ser letrado digitalmente vai além de simplesmente saber utilizar dispositivos eletrônicos e digitais, mas sim interagir com TDICs em "diferentes práticas sociais por ela[s] mediadas e circulantes no meio digital" (SILVA, 2016, p. 39).

Rojo (2013, p. 7) defende que devemos "buscar no ciberespaço um lugar para se encontrar, de maneira crítica, com diferenças e identidades múltiplas". Logo, é crucial entender que o papel da escola no processo de inclusão digital deve, primordialmente, se centrar no conhecimento significativo e inovador visando à formação humana e, a partir do uso das TDICs, tornar o aluno agente ativo de mudanças, e não somente prepará-lo para a inserção no mercado de trabalho.

Tendo discutido como o ambiente escolar está imerso no universo de TDICs, poderíamos pensar que não seria difícil implementar um modo de ensino remoto emergencial para manter a escola e a educação vivas durante a pandemia do novo coronavírus enquanto a população precisa manter-se isolada em suas residências. Porém, além de questões sobre a conscientização de como as TDICs podem ser integradas a uma metodologia bem construída com objetivos de desenvolver letramentos digitais no ensino de línguas estrangeiras, temos o desafio de transpor a escola, que foi estruturada para existir no modo presencial, para o modo remoto a distância, o que vem sendo nomeado como ensino remoto emergencial.

Buscamos, nesta seção, discutir CALL, EaD e ensino remoto como modalidades diferentes, mas que se relacionam a partir de pontos em comum: a integração das TDICs e as práticas sociais e de linguagem construídas por meio delas, as quais, por sua vez, requerem novos papeis de professor e alunos críticos e autônomos. Entretanto, distinções são estabelecidas ao pensarmos o ensino remoto como uma adaptação das aulas presenciais em que não há o desenvolvimento próprio dos modelos pedagógicos da $\mathrm{EaD}$, principalmente porque o ensino remoto emergencial vem sendo entendido como uma alternativa de continuar atividades de ensinoaprendizagem em uma escola que foi pensada e organizada para o modo presencial em sua origem e tradição (HODGES, 2020). Nesse debate, há a necessidade de compreender os aspectos essenciais da $\mathrm{EaD}$, suas possibilidades e desafios, assim como o papel das TDICs no ensino de línguas (CALL) para podermos desenvolver e implementar planos de ensino remoto emergencial nos contextos escolares.

Tendo em mente todos esses aspectos aqui discutidos em torno do ensino de línguas mediado por tecnologias e sobre as possibilidades e limitações da EaD diante do cenário emergencial de aulas remotas, entendemos que muitas escolas, professores, famílias e estudantes enfrentaram e ainda enfrentam inúmeros desafios para realizar as mudanças necessárias para que 0 ensino remoto seja produtivo. Para compreendermos melhor esses desafios, propomos este estudo cuja metodologia descrevemos a seguir.

\section{METODOLOGIA DA PESQUISA}

Este é um estudo qualitativo interpretativista (Silverman, 2000) de caráter diagnóstico que teve como objetivo compreender os desafios enfrentados pelos estudantes da rede pública e da rede particular de ensino básico no estado do Ceará do ponto de vista 
dos professores de línguas estrangeiras em serviço. Para isso, aplicamos um questionário digital em grupos on-line de professores de idiomas do estado do Ceará e obtivemos duzentas (200) respostas de forma voluntária e anônima. A aplicação ocorreu durante as duas primeiras semanas do mês de abril de 2020, momento em que as secretarias de educação tanto estadual quanto municipais começavam a ofertar cursos de formação em TDICs e EaD para apoiar professores no planejamento e implementação das atividades letivas no modo remoto.

O questionário aplicado continha dezessete (17) perguntas fechadas e uma pergunta final aberta. As perguntas fechadas eram marcadas como obrigatórias e a pergunta aberta como opcional. Para esta última pergunta aberta opcional, obtivemos cento e sessenta e quatro (164) respostas, o que indica a voluntariedade dos professores em participar da pesquisa, já que eram perguntas abertas e opcionais. Entre as dezessete questões, seis (6) investigavam o perfil do professor e as demais identificavam as suas experiências e percepções com e sobre o ensino de línguas durante a quarentena em isolamento social. A partir das respostas, do corpo de 200 professores participantes, identificamos que cento e três (103) dos respondentes atuavam somente na rede pública, setenta e quatro (74) somente na rede particular e vinte e três (23) dos respondentes mencionaram atuar em ambas as redes pública e particular. Dos níveis e/ou modalidades de ensino, vinte e um (21) professores atuavam no Ensino Infantil e Fundamental I, quarenta e quatro (44) no Ensino Fundamental II, quarenta e dois (42) no Ensino Médio, trinta e dois (32) em cursos de idiomas, quatro (4) em nível superior, quatro (4) em ensino bilíngue, três (3) em Educação de Jovens e Adultos, e os demais, sessenta (60) atuavam em mais de um nível ou modalidade mencionados, principalmente entre as séries do Ensino Fundamental Il e do Ensino Médio. Ademais, o alcance do questionário contemplou cento e vinte (120) professores de Fortaleza e o restante do interior do estado, alcançando todas as regiões, como Sobral (onze respondentes), Quixadá (seis respondentes), Crateús (dois respondentes), Juazeiro do Norte (dois respondentes), entre vários outros, totalizando trinta e sete (37) municípios.

A seguir, apresentamos a análise e discussão apenas das respostas às quatro perguntas que tratavam das percepções dos professores acerca da participação dos seus alunos nas atividades remotas desenvolvidas como parte do plano emergencial durante a pandemia do coronavírus, conforme já discutimos anteriormente. As perguntas eram:

- $\quad \mathrm{Na}$ rede pública, como você avalia a adesão dos seus alunos nas atividades remotas durante a quarentena?

- $\quad$ Na rede particular, como você avalia a adesão dos seus alunos nas atividades remotas durante a quarentena?

- Sobre os alunos com baixa adesão às atividades remotas, quais as causas já identificadas?

- Sobre os alunos com adesão satisfatória às atividades remotas, quais as causas já identificadas? Para a apresentação dos resultados, organizamos os dados analisados conforme as descobertas, que apresentamos juntamente com a discussão a seguir.

\section{DESCOBERTAS E DISCUSSÃO}

Os dados nos mostraram que, do ponto de vista dos professores, a adesão às atividades no modo remoto foi maior entre os alunos da rede particular em comparação com os alunos da rede pública. Os professores da rede particular avaliaram que a participação da maior parte dos seus alunos era boa ou muito boa, englobando $57 \%$ dos estudantes aderindo ao ensino remoto com essa performance (conforme mostra o gráfico 1 a seguir).

Gráfico 1: Adesão dos alunos da rede particular às atividades remotas.

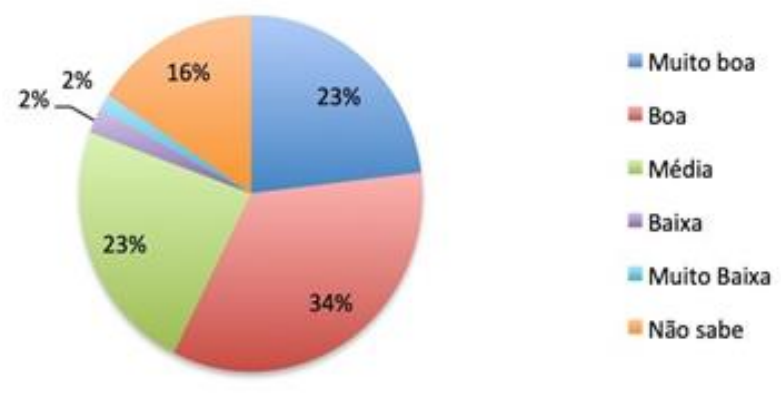


Fonte: autoria nossa

Na rede pública, os professores avaliaram que a adesão da maior parte dos seus alunos às atividades remotas foi média e baixa, totalizando $52 \%$ (conforme mostra o gráfico 2).

Gráfico 2: Adesão dos alunos da rede pública às atividades remotas

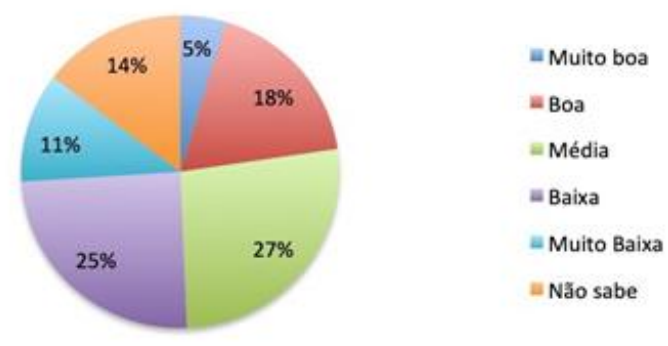

Fonte: autoria nossa

A tendência das respostas tanto para a rede pública como a particular alinha-se ao padrão socioeconômico dos estudantes da rede pública em comparação com a particular. Esperava-se que esses últimos tivessem mais acesso às tecnologias digitais atuais assim como estrutura residencial para realizar seus estudos em casa. Isso também foi apontado nas pesquisas trazidas na introdução deste estudo publicadas nos jornais locais, o que corrobora nossos resultados.

Também nos chama a atenção o fato de que $14 \%$ das respostas dos professores da rede pública revelaram que não sabiam responder. Uma possível justificativa para isso é que muitos dos estudantes da rede pública não estavam sendo alcançados pelas propostas de ensino remoto, o que foi discutido na introdução deste trabalho acerca das zonas de invisibilidade, assim como algumas escolas e/ou professores não estavam desenvolvendo atividades remotas até aquele momento. Nos surpreende, no entanto, a descoberta de que $16 \%$ dos professores da rede particular também não souberam responder à pergunta que pedia avaliação da adesão dos seus alunos às atividades remotas. Devido ao previsto acesso dos estudantes da rede particular às tecnologias, o esperado era que todos os alunos da rede particular estivessem sendo atendidos.
Comparando os resultados, vemos que apenas $4 \%$ das respostas avaliavam a adesão dos alunos da rede particular como baixa ou muito baixa, enquanto que $5 \%$ das respostas dos professores da rede pública avaliava a participação dos estudantes como muito boa, $18 \%$ como boa, e $36 \%$ como baixa ou muito baixa. Isso nos mostra que há uma divisão expressiva entre a percepção dos professores sobre a participação dos estudantes nas atividades remotas durante a pandemia quando comparamos a rede pública e a rede particular, o que pode apontar para um novo tipo de "digital divide", nos termos de Prensky (2000), também discutido anteriormente. No contexto aqui pesquisado, porém, a divisão não parece ser entre os nativos digitais e os imigrantes digitais, mas sim entre os que têm acesso às tecnologias digitais e os que não têm. $O$ gráfico 3 a seguir ilustra melhor 0 que os resultados nos apontam como um novo "digital divide" encontrados nos dados deste estudo:

Gráfico 3: Adesão dos alunos da rede pública e particular às atividades remotas.

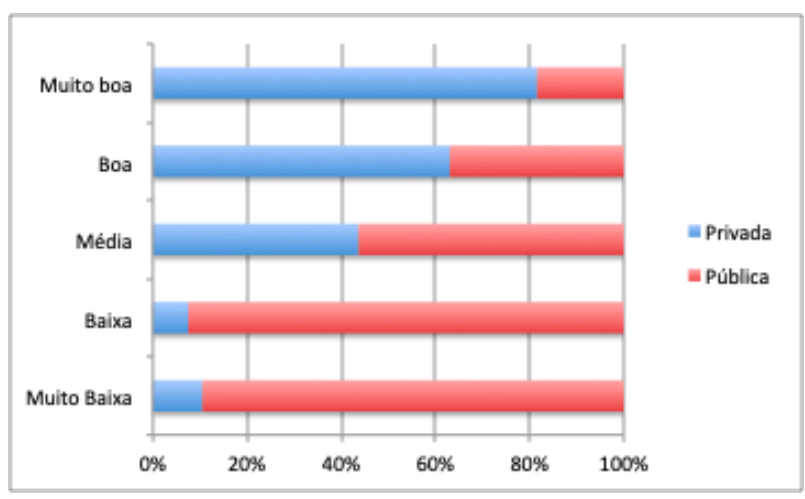

Fonte: autoria nossa

No gráfico 3, fica bastante visível a proporção de adesão considerada muito boa para a rede privada e a proporção de adesão considerada muito baixa para a rede pública, mostrando um recorte transversal ao longo dos cinco tipos de resposta sobre ambas as redes. Entre as razões que justificaram a alta ou a baixa adesão dos alunos às atividades remotas, quando perguntados sobre as causas que pudessem justificar a baixa adesão dos estudantes às atividades remotas, duas razões foram mais salientes nas respostas dos professores, uma relacionada a autonomia, outra relacionada ao acesso à tecnologia: (i) o aluno não tinha o hábito de realizar atividades remotas com tecnologias e com autonomia (118 
respostas, 59\% das respostas); e (ii) o aluno não tinha internet suficiente para 0 desenvolvimento das atividades remotas (117 respostas, 58,5\%), ou não tinha internet de nenhuma forma (99 respostas, 49,5\%), e/ou não tinha dispositivos tecnológicos em casa, entre as opções de laptop, PC ou tablet (109 respostas, 54,5\%).

Essas duas razões principais apontam para o papel do aluno nas atividades a distância, que pressupõe um aprendiz ativo e autônomo, organizado, motivado e disposto a realizar tarefas com tecnologias integradas, características essenciais de CALL e da $\mathrm{EaD}$, conforme discutimos na fundamentação teórica anteriormente. Vemos que essas características se impõem sobre uma cultura tradicional de aprender ainda muito centrada no professor, gerando mais desigualdades entre os grupos, conforme também discutimos na fundamentação teórica (CHAPELLE, 2001, 2003; CRYSTAL, 2001; LAMY \& HAMPEL, 2007). Um depoimento voluntário deixado ao final do questionário também aponta para essa percepção:

Este é um caminho que está sendo construído à medida que trilhamos e, às vezes, é preciso voltar ao básico (ensinar como usar um aplicativo/programa) para ter sucesso nas aulas. $O$ aluno mais jovem não tem necessariamente a habilidade do aprender digital. Muitas vezes sua atuação é de consumo e não de protagonismo.

A falta de acesso a TDICs, segunda razão em termos de recorrências encontradas nos dados que justificou a baixa adesão dos alunos ao ensino remoto, aponta para as desigualdades sociais. Isso também foi enfatizado nas respostas abertas voluntárias deixadas ao final do questionário:

No caso do Ensino Fundamental I nem sempre o(s) responsável(s) pode acompanhar e ajudar na compreensão e resolução das atividades propostas. Mesmo com o isolamento, muitos continuam precisando trabalhar. Assim, várias crianças não tem como acessar a aula no horário previsto, pois na maioria elas usam o celular dessa(s) pessoa(s).

Em minha opinião o sistema de aulas online é um sistema visivelmente excludente.
Encontramos, ainda que menos recorrente, mas igualmente relevante, uma terceira razão para a baixa adesão dos alunos e que também vai no sentido socioeconômico das famílias: o estudante não tinha apoio familiar para realizar as atividades remotas (89 respostas, 44,5\%) ou não tinha espaço adequado na sua residência para realizar as atividades remotas (63 respostas, 31,5\%). Esse resultado corrobora a pesquisa realizada por Andrade (2020) e Cosme (2020), discutidas na introdução deste artigo.

Houve também um número significativo de respostas apontando que o aluno não tem disposição para realizar as atividades remotas (87 respostas, $43,5 \%$ ), ou que o aluno tem dificuldades ou não sabe usar os dispositivos e ferramentas tecnológicas (78 respostas, 39\%), o que mais uma vez aponta para a falta de autonomia do aluno, característica necessária para o desenvolvimento de atividades remotas. Além da falta de autonomia, outra razão para a baixa adesão às atividades remotas apontadas pelos professores, com 42 respostas (21\%), foi de que o aluno não tem condições emocionais para realizar atividades remotas (por fome, violência, grupo de risco, doenças ou mortes na família). Poucos professores julgaram que a baixa adesão se devia ao aluno não ter tempo para realizar as atividades remotas por questões de trabalho (18 respostas, 9\%).

Entre as nove respostas finais escritas voluntariamente em "outros", os professores respondentes salientaram a baixa competência leitora dos alunos e, mais uma vez, a falta de interesse. Isso também corrobora $o$ que discutimos sobre a predominância de textos escritos na CMC que requer letramentos que vão além do texto verbal, ricos em outras semioses que requerem leitores críticos capazes de reconhecer modos de significação diversos, o que também foi discutido anteriormente (NASCIMENTO et al, 2011; KNOLL, 2015).

Quando perguntados sobre as razões para a participação satisfatória dos alunos às atividades remotas propostas, considerando a porcentagem de alunos que participam das atividades, os professores responderam que: (i) os alunos tinham condições estruturais satisfatórias nas suas residências (170 
respostas, 85\%); (ii) os alunos tinham motivação para realizar as tarefas (139 respostas, 69,5\%); (iii) os alunos tinham disposição para interagir com professores e com os colegas (131 respostas, 65,5\%); (iv) os alunos estavam habituados a realizar atividades remotas com tecnologias, que já era uma prática da escola/professor anterior à pandemia (57 respostas, $28,5 \%)$.

Chama-nos a atenção a segunda razão para uma participação satisfatória nas atividades remotas, apontada pelos professores, que é o papel da família apoiando os estudantes nas atividades de ensinoaprendizagem (153 respostas, 76,5\%). A participação da família parece apontar um caminho para compensar a falta de autonomia dos estudantes e a distância espaciotemporal dos professores. Em uma das respostas abertas, um respondente salientou que "os pais obrigam os estudantes a estudar em casa" é uma das razões principais para a adesão do estudante às atividades remotas. Outro professor comentou ao final do questionário:

No momento atual, na situação da minha escola, alunos e professores, escola e família estão todos aprendendo juntos.

Por fim, entre as cento e sessenta e quatro (164) respostas abertas deixadas ao final do questionário de forma voluntária, quando perguntados se gostariam de acrescentar algo que não havia sido abordado, identificamos trinta e três respostas em que professores são, de modo geral, otimistas com o tipo de ensino remoto. Um exemplo disso pode ser visto no excerto abaixo:

É gratificante saber que muitos alunos, em especial da rede privada de ensino, têm se adaptado de maneira rápida a esse novo método, proporcionando assim o seu contínuo aprendizado no conforto e na privacidade de seus lares.

Porém, os professores reconhecem que há necessidade de mais estudo e pesquisa para compreendermos melhor as dificuldades e obstáculos com objetivo de superá-los:

O momento tem requerido dos docentes rever suas posturas e ser sensível a cada situação, os alunos da rede pública tem muitas limitações que torna o processo de aquisição do conhecimento ainda mais complexo. Mas constato que com estímulo a maioria passa a aderir as propostas.

Não está claro como proceder com alunos que não podem ou não estão participando a contento, mesmo que com atividades mais simples. Tem alunos sendo deixados para trás em todo esse processo, e pouca gente sabe como isso será resolvido.

A seguir, concluímos este estudo trazendo algumas considerações finais e encaminhamentos para ações futuras.

\section{CONSIDERAÇÕES \\ FINAIS \\ E ENCAMINHAMENTOS}

Este estudo teve foco no ensino de idiomas nas redes pública e particular de ensino no estado do Ceará com objetivo de compreender melhor, do ponto de vista dos professores em serviço, como os estudantes têm aderido ao plano emergencial de ensino de língua estrangeira no modo remoto, principalmente mediado por tecnologias digitais, e as razões para a sua adesão.

A partir dos dados referidos, notamos que a baixa adesão é prioritariamente justificada por questões anteriores à pandemia, como a falta de autonomia do aluno, acesso limitado às tecnologias e o despreparo para o uso delas. Também ficou evidenciado que o apoio familiar nas residências era fundamental para o aproveitamento satisfatório dos alunos ao realizarem as atividades remotas. Isso aponta que não só questões socioeconômicas são fundamentais para a continuidade do processo de aprendizagem no modo remoto emergencial, mas também a autonomia do estudante para realizar as atividades propostas. Evidenciou-se que, para a inclusão de todos, não apenas é necessário garantir que os estudantes tenham acesso às tecnologias, mas também trabalharmos no desenvolvimento de suas competências e letramentos digitais.

Acreditamos que os baixos letramentos dos estudantes para lidarem efetivamente com a interação on-line, de um modo geral, não são obstáculos à implementação de um tipo de ensino remoto - ao 
contrário, é sobre eles que os professores poderiam estar atuando intensamente neste momento, o que parece bastante apropriado, já que para uma boa condução do ensino remoto é necessário o desenvolvimento dos letramentos digitais tanto dos professores como dos alunos. Desse modo, nossa sugestão é que os professores de línguas, seja materna ou estrangeira, pudessem, neste momento, atuar no desenvolvimento dos letramentos digitais e críticos dos estudantes, em vez de insistirem em trabalharem os conteúdos anteriormente previstos para o ensino tradicional da sala de aula.

Evidenciou-se, ainda, que a participação da família parece apontar um caminho para compensar a falta de autonomia dos estudantes e a distância espaciotemporal dos professores. Os resultados, de um modo geral, apontam que a garantia da qualidade no ensino remoto emergencial durante a pandemia requer que professores, escolas, estudantes e famílias trabalhem em conjunto na dimensão da metodologia de ensino e nas condições mentais e emocionais dos estudantes. Ao mesmo tempo, verificamos que há a necessidade da atuação do Estado na garantia das condições estruturais dos estudantes para que tenham acesso às tecnologias, pois garantir o acesso a dispositivos tecnológicos e internet está fora do domínio e das competências das escolas e das famílias.

Esta pesquisa tem limitações, sendo uma delas verificar as condições dos estudantes a partir do ponto de vista dos professores. Porém, salientamos que o olhar atento aos alunos é crucial não somente para evitar a evasão escolar, mas também para garantir a continuidade dos estudos de maneira efetiva e o seu desenvolvimento saudável nos âmbitos cognitivo e emocional.

\section{REFERÊNCIAS}

ANDRADE, D. Excluídos do ensino na pandemia. In: Jornal O Povo, de 13 de julho de 2020. Disponível em: https://mais.opovo.com.br/reportagens-especiais/semacesso-ao-ensino-na- pandemia/2020/07/13/excluidos-do-ensino-napandemia.html. Acesso em 13 de jul. de 2020.

BELLONI, M. L. Ensaio sobre a educação a distância no Brasil. In: Educação e Sociedade. Ano XXIII, n. 78. Campinas, 2002 (p. 117-142).

BELZ, J. A. Institutional and individual dimensions of transatlantic group work in network-based language teaching. In: ReCALL. 13 (2), 2001 (p. 213-231)

COSME, I. Professores mudam rotina para alcançar estudantes. In: Jornal O Povo, de 13 de julho de 2020. Disponível em: https://mais.opovo.com.br/reportagens-especiais/semacesso-ao-ensino-na-

pandemia/2020/07/13/professores-mudam-rotinapara-alcancar-estudantes.html. Acesso em 13 de jul. de 2020.

GARCIA ARETIO, L. Para uma definição de educação à distância. Tecnologia Educacional. Vol. 16, n. 56-61. Rio de Janeiro, 1987. (p. 78-79).

HODGES, C. et al. The Difference Between Emergency Remote Teaching and Online Learning.

EDUCAUSE, [s. I.], 27 mar. 2020. Disponível em: https://er.educause.edu/articles/2020/3/the-differencebetween-emergency-remote-teaching-and-onlinelearning. Acesso em: 3 dez. 2020.

KNOLL, Graziela Frainer. Multimodalidade, texto e contexto: categorias úteis à análise da charge. Revista (Con) Textos Linguísticos. UFES, v. 9, n. 12, p. 57-74, 2015.

LAMY, M-N .\& HAMPEL, R. Online Communication in Language Teaching and Learning. London: Palgrave Macmillan, 2007.

LANTOLF, J.P. (ed.) Sociocultural theory and second language learning. Oxford: Oxford University Press, 2000. 
LAVE, J., \& WENGER, E. Situated learning: Legitimate peripheral participation. Cambridge, UK: Cambridge University Press, 1991.

LEVY, M. Scope, goals and methods in CALL research: questions of coherence and autonomy. ReCALL, 12, 2000 (p. 170-195).

MOREIRA, M. G. A composição e o funcionamento da equipe de produção. In: LITTO, F. M.\& FORMIGA, M. M. M. (Orgs.) Educação a Distância: o estado da arte. São Paulo: Pearson Education do Brasil, 2009 (p. 370378).

MOTA, R. A Universidade Aberta do Brasil. In: LITTO, F. M.\& FORMIGA, M. M. M. (Orgs.) Educação a Distância: o estado da arte. São Paulo: Pearson Education do Brasil, 2009 (p. 297-303).

NASCIMENTO et al. Multiletramentos: iniciação à análise de imagens. Linguagem e ensino, Pelotas, v. 14, n. 2, p. 529-552, jul./dez. 2011.

PRENSKY, M. Teaching Digital Natives: Partnering for real learning. Thousand Oaks: Corwin SAGE Company, 2010.

ROJO, R. H. (Org.). Escol@ Conectada - os multiletramentos e as TICs. São Paulo: Parábola Editorial, 2013.

SANTOS, B. S. A cruel pedagogia do vírus. Coimbra: Almedina, 2020.

SILVA, Edna Marta Oliveira da. O letramento crítico e o letramento digital: a web no espaço escolar. Revista X, UFPR, v. 2, p. 32-50, 2016. Disponível em: <https://revistas.ufpr.br/revistax/article/view/46572/29 526>. Acesso em: 15 jun. 2020.

SILVERMAN, D. Doing qualitative research: A practical handbook. London: SAGE, 2000.
VILAÇA, Márcio; ARAÚJO, Elaine. Tecnologia, Sociedade e Educação na Era Digital. Universidade UNIGRANRIO, 2016.

VYGOSTKY, L. S. (1934) Pensamento e linguagem. São Paulo: Martins Fontes, 2000.

WALKER, Aisha; WHITE, Goodith. Technology Enhanced Language Learning: connecting theory and practice. Oxford, 2013.

WARSCHAUER, M. Computer-mediated collaborative learning: theory and practice. In: The modern language journal. VI. 81, 1997 (p. 470-481).

WARSCHAUER, M. Researching technology in TESOL: Determinist, instrumental, and critical approaches. In: TESOL quarterly. VI. 32, 1998 (p. 757761).

WHITE, C. Language learning in distance education. Cambridge: Cambridge University Press, 2003.

TUROLO DA SILVA, Andreia et al. Os alunos das redes pública e particular do Ceará em tempos de pandemia na visão dos professores de línguas estrangeiras. Signo, Santa Cruz do Sul, v. 46, n. 85, p. 122-133, jan. 2021. ISSN 1982-2014. Disponível em: $<$ https://online.unisc.br/seer/index.php/signo/article/view/ 15580>. doi:https://doi.org/10.17058/signo.v46i85.15580. 